\title{
Effect of packing materials on the decomposition of tetrafluoroethane in a packed-bed dielectric barrier discharge plasma reactor
}

\author{
M. S. Gandhi • Y. S. Mok
}

Received: 18 January 2012/Revised: 26 July 2013/ Accepted: 3 November 2013/Published online: 26 November 2013 (C) Islamic Azad University (IAU) 2013

\begin{abstract}
The performance of 1,1,1,2-tetrafluoroethane or HFC-134a decomposition and the formation of byproducts in a dielectric barrier discharge plasma reactor were studied with different packing systems such as $\alpha-\mathrm{Al}_{2} \mathrm{O}_{3}$ (porous and nonporous), $\gamma-\mathrm{Al}_{2} \mathrm{O}_{3}$ (porous) and $\mathrm{ZrO}_{2}$ (nonporous). Experimental variables such as reactor temperature, initial HFC-134a concentration and oxygen levels were chosen for the performance analysis. Among the packing systems, the porous $\gamma-\mathrm{Al}_{2} \mathrm{O}_{3}$ and $\alpha-\mathrm{Al}_{2} \mathrm{O}_{3}$ decomposed HFC-134a much more effectively than the nonporous $\alpha-\mathrm{Al}_{2} \mathrm{O}_{3}$ and $\mathrm{ZrO}_{2}$. The combination of the plasma with the porous $\gamma$ $\mathrm{Al}_{2} \mathrm{O}_{3}$ was found to cover a wide range of initial concentration. The decomposition efficiency tended to increase with the addition of oxygen up to $2 \%$, but further increase in the oxygen led to a decrease. As well as carbon oxides $\left(\mathrm{CO}_{2}\right.$ and $\left.\mathrm{CO}\right)$, significant amounts of unwanted byproducts such as $\mathrm{COF}_{2}$ and $\mathrm{CF}_{4}$ were also identified in the effluent gas with the nonporous $\alpha-\mathrm{Al}_{2} \mathrm{O}_{3}$ and $\mathrm{ZrO}_{2}$. On the contrary, with the porous $\gamma-\mathrm{Al}_{2} \mathrm{O}_{3}$ and $\alpha-\mathrm{Al}_{2} \mathrm{O}_{3}$, such unwanted byproducts were considerably suppressed, enhancing the formation of $\mathrm{CO}_{2}$ and $\mathrm{CO}$.
\end{abstract}

Keywords 1,1,1,2-Tetrafluoroethane - Catalysis · Dielectric barrier discharge $\cdot$ Packing materials $\cdot$ Plasma

\section{Introduction}

The use of hydrofluorocarbons (HFCs) as an alternative refrigerant for the replacement of chlorofluorocarbons was

M. S. Gandhi · Y. S. Mok ( $\varangle)$

Department of Chemical and Biological Engineering, Jeju National University, Jejudaehakno 102, Cheju 690-756, Korea e-mail: smokie@jejunu.ac.kr an important step in protecting the stratospheric ozone. Consequently, 1,1,1,2-tetrafluoroethane or HFC-134a has been widely used in automobile air conditioners and domestic refrigeration. Typically, this gas exhibits high global warming potential due to its ability to absorb infrared radiation and relatively long atmospheric lifetime (Ohno et al. 2007). The Natural Resources Defense Council also claims that the Environmental Protection Agency may eliminate HFC-134a from the list of acceptable substitutes for motor vehicle air conditioning systems. Therefore, the efficient removal techniques are desperately required for secure disposal of such a gas before release into the atmosphere.

Recently, nonthermal plasma decomposition seems to be an appropriate and promising technique for reducing the emission of various gaseous pollutants, including fluorinated compounds (Mok et al. 2008; Zhu et al. 2008), chlorofluorocarbons (Kang 2002), volatile organic compounds (Holzer et al. 2002), nitric oxide (Chen and Mathur 2003) sulfur dioxide (Ma et al. 2002), hydrogen sulfide (Yavorsky and Znak 2009), etc. Several researchers have proposed a variety of plasma discharge techniques such as pulsed corona discharge, microwave plasma discharge and dielectric barrier discharges (DBD), so far. Among them, the DBD plasma reactor appears to become very attractive due to its compact structure and its capability of producing chemically reactive species at ambient pressure and delivering high average power without significantly changing the gas temperature (Kogelschatz 2003).

For the purpose of improving the performance of the DBD reactor, recent studies have been focused on the combination with catalysts such as $\mathrm{Al}_{2} \mathrm{O}_{3}, \mathrm{AlPO}_{4}, \mathrm{TiO}_{2}, \mathrm{Pt}$, $\mathrm{MnO}_{2}$, zeolite and iron oxide. Numerous studies have indicated that the decomposition of fluorinated compounds depends largely on the physicochemical properties of 
catalyst, applied voltage, gas residence time and gaseous additives such as oxygen, helium and argon. (Futamura and Gurusamy 2005; Kim et al. 2010; Kuroki et al. 2002). Furthermore, Holzer et al. (2002) pointed out that the porous texture of catalyst mostly favors total oxidation of pollutants than nonporous materials, implying that the structure of catalyst is also an important factor in the decomposition of fluorinated compounds. Xu et al. (2007) reported that the decomposition of $\mathrm{CF}_{4}$ depends more strongly on the chemical properties of porous $\gamma$-alumina than its physical properties, and they concluded that $\gamma$ alumina is an effective phase for decomposing fluorinated compounds. With the above background, we have investigated the decomposition of HFC-134a with different packing materials. Besides, the effect of several parameters such as reactor temperature, initial concentration of HFC134a and oxygen content was examined. The decomposition products were analyzed by using a Fourier transform infrared (FTIR) spectrometer.

\section{Materials and methods}

The DBD plasma reactor used in this experiment was formed with a ceramic tube having respective inner and outer diameters of 24 and $28 \mathrm{~mm}$. An 8-mm stainless steel screw was coaxially inserted into the ceramic tube as the discharging electrode to which alternating current (AC) high voltage was applied. The outer surface of the ceramic tube was wrapped with a copper foil and was connected to the ground electrode. The applied voltage and frequency were $10-16 \mathrm{kV}$ and $400 \mathrm{~Hz}$, respectively. The input power was measured by a digital power meter (Model WT200, Yokogawa, Japan). The DBD reactor prepared as above was covered with a heating tape to obtain desired temperatures. The temperature was controlled by a proportional-integral-derivative controller equipped with a thermocouple. The tip of the thermocouple was placed at the midpoint of the outer surface of the reactor. The schematic diagram of the experimental setup for decomposing HFC-134a is depicted in Fig. 1. The reactor was packed with 3-mm $\mathrm{ZrO}_{2}$ (nonporous), 3-mm $\alpha-\mathrm{Al}_{2} \mathrm{O}_{3}$ (nonporous), $3-\mathrm{mm} \alpha-\mathrm{Al}_{2} \mathrm{O}_{3}$ (porous) or $3-\mathrm{mm} \gamma-\mathrm{Al}_{2} \mathrm{O}_{3}$ (porous) to a volume of $127 \mathrm{~cm}^{3}$. The Brunauer-EmmettTeller (BET) surface areas of porous $\alpha-\mathrm{Al}_{2} \mathrm{O}_{3}$ and $\gamma-\mathrm{Al}_{2} \mathrm{O}_{3}$ were measured to be 195.7 and $175 \mathrm{~m}^{2} \mathrm{~g}^{-1}$, while those of nonporous $\mathrm{ZrO}_{2}$ and nonporous $\alpha-\mathrm{Al}_{2} \mathrm{O}_{3}$ were negligible. The effective reactor length for creating plasma was $145 \mathrm{~mm}$.

As shown in Fig. 1, HFC-134a was diluted by pure nitrogen and a small amount of pure oxygen, which was fed to the reactor from the top and then exhausted from the

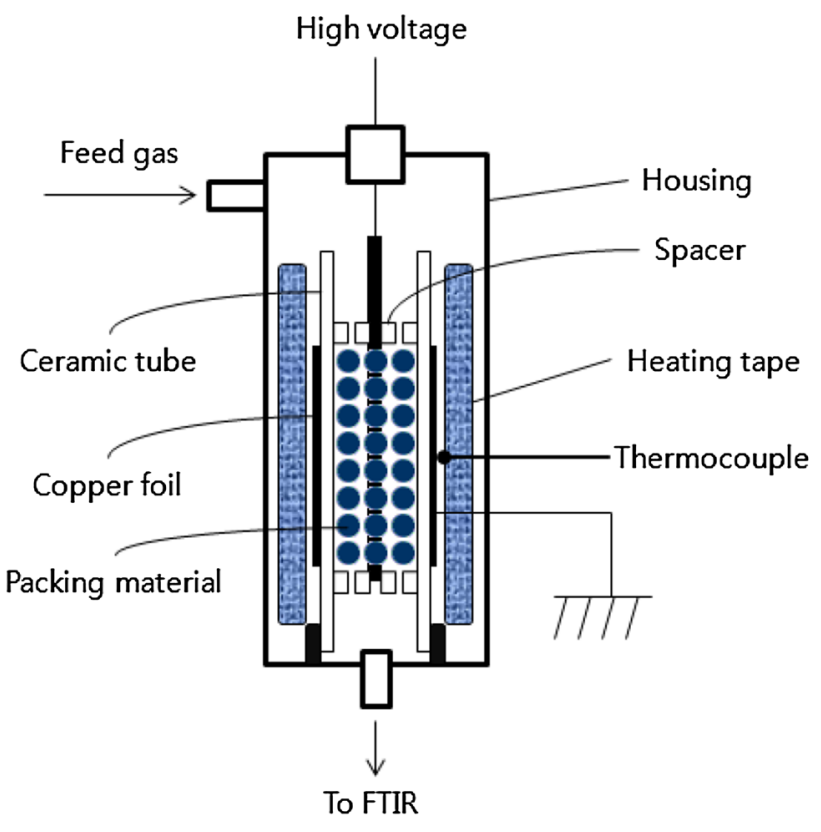

Fig. 1 Schematic diagram of the experimental setup

bottom. The total gas flow rate was controlled to $1.0 \mathrm{~L} \mathrm{~min}^{-1}$ by using mass flow controllers (MKS Instruments, Inc., USA). The initial concentration of HFC-134a was changed from 2,000 to 6,000 ppm (parts per million, volumetric). The content of oxygen was varied from 0 to $6.0 \%(\mathrm{v} / \mathrm{v})$. The temperature effect on the decomposition of HFC-134a was examined in the range up to $500{ }^{\circ} \mathrm{C}$. A FTIR spectrometer (Bruker IFS 66/S, Germany) was employed to determine the concentration of HFC-134a and by-products. The decomposition efficiency was defined as $\left(\mathrm{C}_{0}-\mathrm{C}\right) / \mathrm{C}_{0} \times 100$, where $\mathrm{C}_{0}$ and $\mathrm{C}$ are the concentrations at the inlet and outlet of the reactor, respectively. HFC-134a and by-products were assigned in the FTIR spectra, and subsequently, the measured absorbance of each compound was converted into concentration units. The morphological structures of the packing materials were characterized by a field emission scanning electron microscope (SEM) (JEOL, JEM1200EX II).

\section{Results and discussion}

Effect of packing material type on the decomposition of HFC-134a

The surface morphologies of the packing materials observed by SEM are given in Fig. 2. From the surface morphologies, it is easily understood that the porous $\alpha$ $\mathrm{Al}_{2} \mathrm{O}_{3}$ and $\gamma-\mathrm{Al}_{2} \mathrm{O}_{3}$ provide high effective surface areas for catalytic reactions, compared to the nonporous $\alpha-\mathrm{Al}_{2} \mathrm{O}_{3}$ and $\mathrm{ZrO}_{2}$. The decomposition of HFC-134a as a function of 

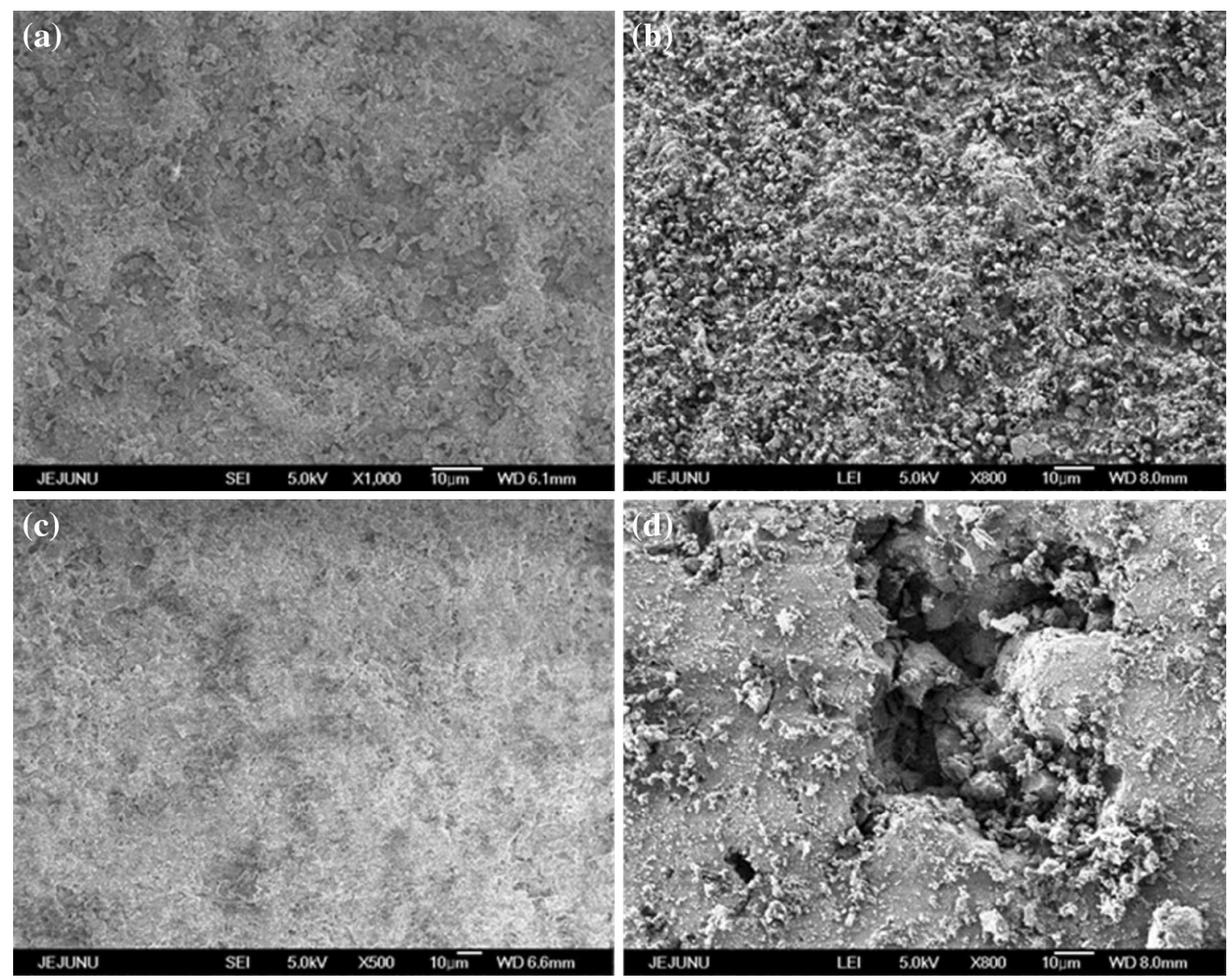

Fig. 2 SEM images of the packing materials: a nonporous $\alpha-\mathrm{Al}_{2} \mathrm{O}_{3}$, b porous $\alpha-\mathrm{Al}_{2} \mathrm{O}_{3}, \mathbf{c}$ nonporous $\mathrm{ZrO}_{2}$ and $\mathbf{d}$ porous $\gamma-\mathrm{Al}_{2} \mathrm{O}_{3}$

Fig. 3 Decomposition of HFC134a over different packing materials [input power: $60 \mathrm{~W}$; initial HFC-134a: 2,000 ppm; oxygen: $2 \%(\mathrm{v} / \mathrm{v})$ ]

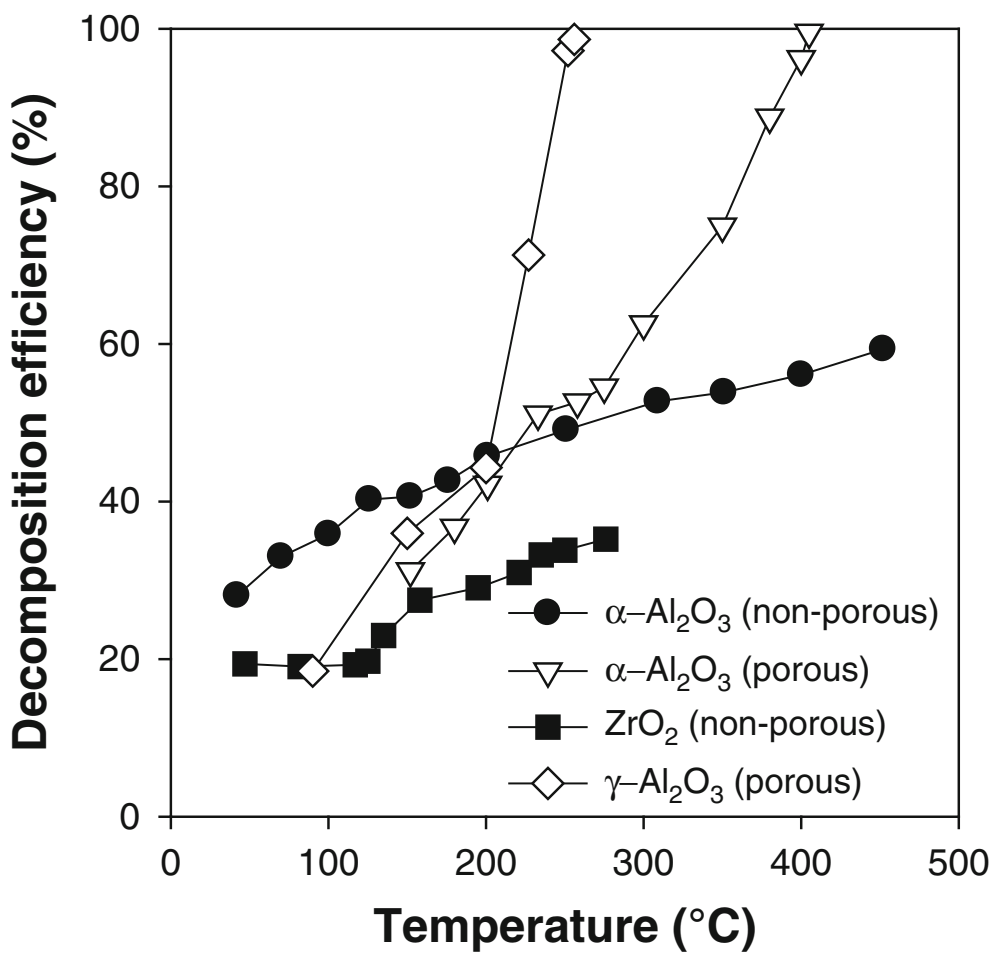


Fig. 4 Decomposition of HFC134a over different packing materials under nonplasma condition [initial HFC-134a: 2,000 ppm; oxygen: $2 \%(\mathrm{v} / \mathrm{v})]$

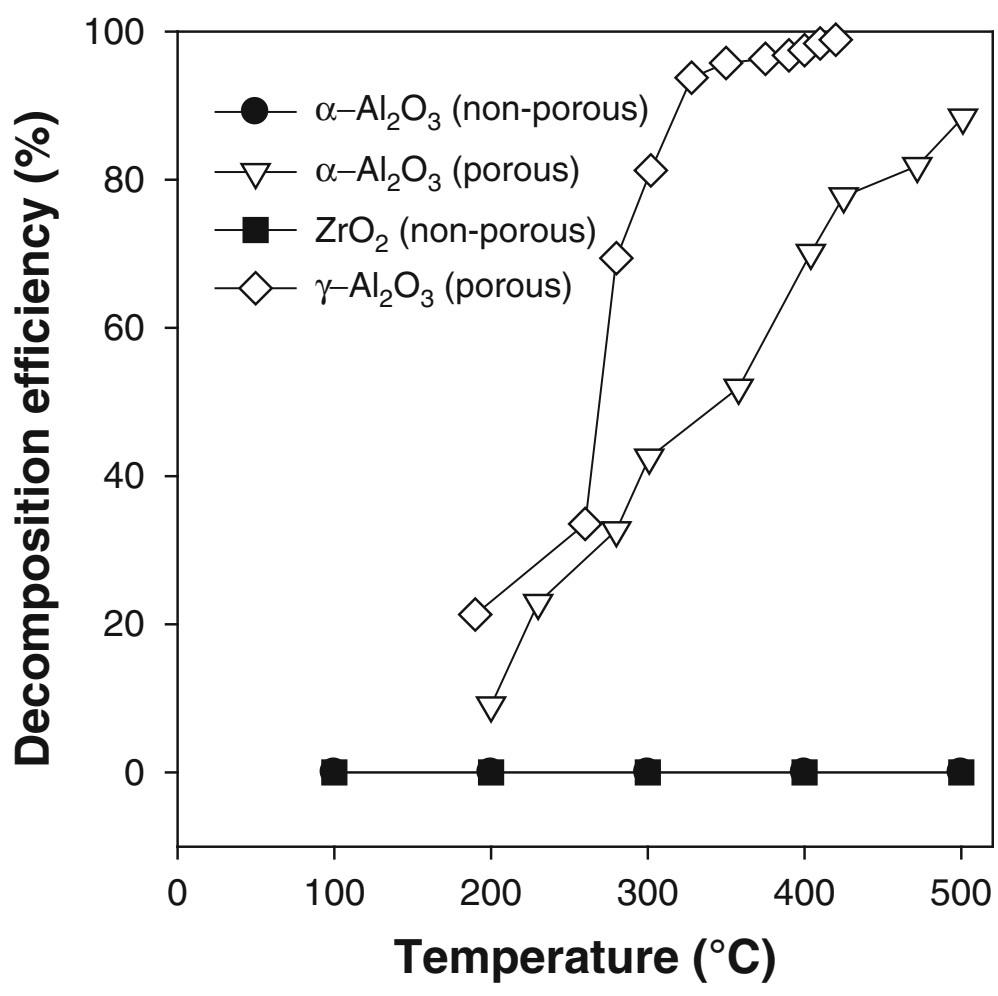

phenomena can also partly explain the enhanced decomposition with the porous packing materials.

Figure 4 shows the HFC-134a decomposition efficiencies over the above-mentioned four different packing materials under nonplasma condition. In the absence of plasma, the packing materials can thermally be activated to exhibit catalysis. A drastic change in the decomposition was observed according to the packing materials used. With the porous $\gamma-\mathrm{Al}_{2} \mathrm{O}_{3}$ and $\alpha-\mathrm{Al}_{2} \mathrm{O}_{3}$, the decomposition started at around $200{ }^{\circ} \mathrm{C}$, and then, the decomposition efficiency gradually increased as the temperature increased. The $\gamma-\mathrm{Al}_{2} \mathrm{O}_{3}$-packed reactor showed a complete destruction of HFC-134a at a temperature less than $420{ }^{\circ} \mathrm{C}$. When the porous $\alpha-\mathrm{Al}_{2} \mathrm{O}_{3}$ was used, maximum reduction of $88 \%$ was observed at around $500{ }^{\circ} \mathrm{C}$. While the porous $\gamma-\mathrm{Al}_{2} \mathrm{O}_{3}$ and $\alpha-\mathrm{Al}_{2} \mathrm{O}_{3}$ exhibited remarkable catalytic activity, no reduction in $\mathrm{HFC}-134 \mathrm{a}$ was observed with the nonporous $\alpha-\mathrm{Al}_{2} \mathrm{O}_{3}$ and $\mathrm{ZrO}_{2}$. Consequently, the porous $\gamma-\mathrm{Al}_{2} \mathrm{O}_{3}$ and $\alpha-\mathrm{Al}_{2} \mathrm{O}_{3}$ should be used for the combination with the plasma.

Effect of initial concentration on the decomposition of HFC-134a

The dependence of HFC-134a decomposition on the initial concentration is shown in Fig. 5. The initial concentration was varied from 2,000 to $6,000 \mathrm{ppm}$ with the oxygen content kept at $2 \%$. The packing material was the porous 
Fig. 5 Effect of initial concentration on the decomposition of HFC-134a (input power: $60 \mathrm{~W}$; oxygen: $2 \%(\mathrm{v} / \mathrm{v})$; packing material: porous $\gamma-\mathrm{Al}_{2} \mathrm{O}_{3}$ )

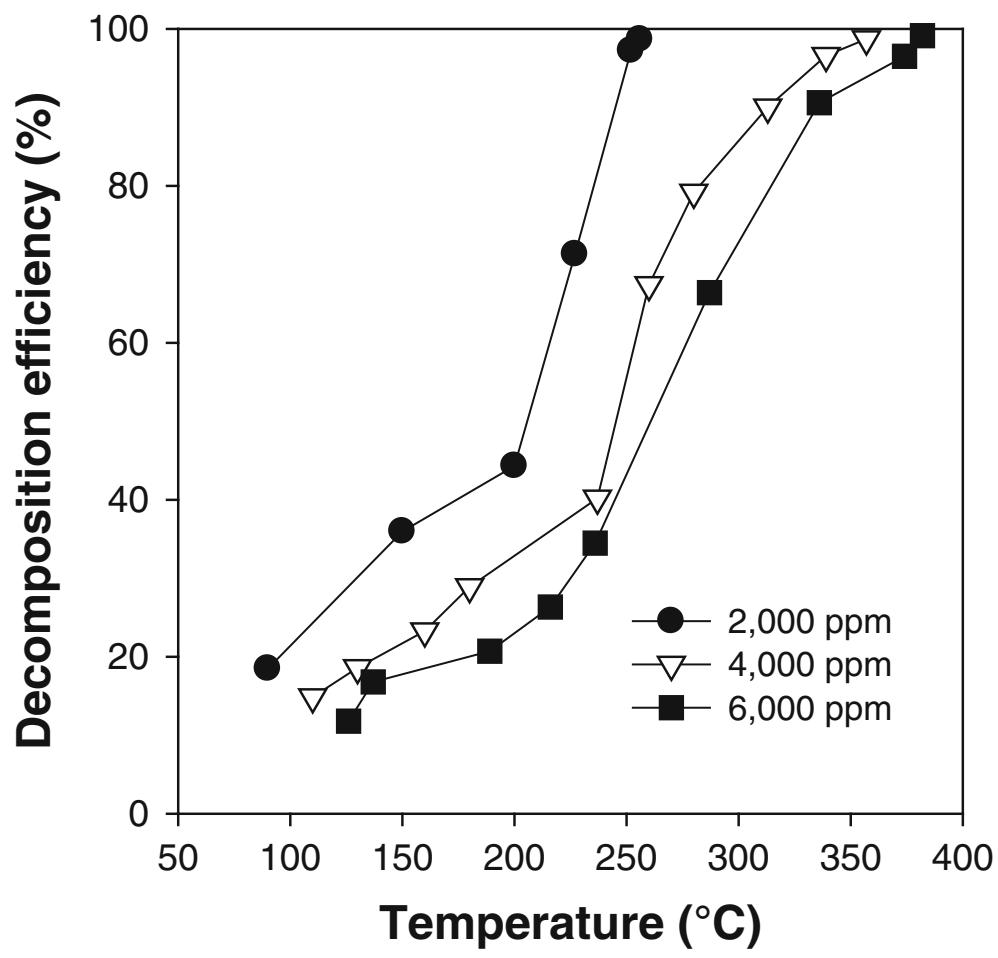

$0.5 \%$ and thereafter a decrease in the decomposition. The difference in the optimal oxygen content between this work and the previous study is understood to have resulted mainly from the difference in the initial concentration.

Formation of by-products

The FTIR spectra of the HFC-134a before and after treatment by nonthermal plasma with different packing materials are depicted in Fig. 7. The initial concentration of HFC-134a was 2,000 ppm with the oxygen content of $2 \%$ $(\mathrm{v} / \mathrm{v})$, and the input power was $60 \mathrm{~W}$. The absorption bands at 1,185 and $1,301 \mathrm{~cm}^{-1}$ before treatment were assigned to HFC-134a and disappeared after treatment. The new peaks around 1,282, 1,255 \& 1,930, 2,360 and 2,112 \& $2,171 \mathrm{~cm}^{-1}$ were attributed to $\mathrm{CF}_{4}, \mathrm{COF}_{2}, \mathrm{CO}_{2}$ and $\mathrm{CO}$, respectively. The FTIR results demonstrate the transformation of HFC-134a and the formation of oxygenated compounds such as $\mathrm{COF}_{2}, \mathrm{CO}_{2}$ and $\mathrm{CO}$. The spectra presented in Fig. 7 show that $\mathrm{H}_{2} \mathrm{O}$ is formed in the presence of porous packing materials $\left(\gamma-\mathrm{Al}_{2} \mathrm{O}_{3}\right.$ and $\left.\alpha-\mathrm{Al}_{2} \mathrm{O}_{3}\right)$. In the plasma reactor, $\mathrm{H}_{2} \mathrm{O}$ will lead to the formation of oxidative radicals such as $\mathrm{OH}$ and $\mathrm{HO}_{2}$ that can contribute to the decomposition of HFC-134a. Details are discussed below.

The formation of $\mathrm{COF}_{2}$ from the decomposition of HFC134a with different packing materials is shown in Fig. 8a. As can be seen, the different types of packing materials greatly distinguish the generation of $\mathrm{COF}_{2}$. In the presence of the nonporous $\alpha-\mathrm{Al}_{2} \mathrm{O}_{3}$ and $\mathrm{ZrO}_{2}$ packing material, decomposition of HFC with the addition of oxygen up to 
Fig. 6 Effect of oxygen content on the decomposition of HFC134a (input power: $60 \mathrm{~W}$; initial HFC-134a: 2,000 ppm; packing material: porous $\gamma-\mathrm{Al}_{2} \mathrm{O}_{3}$ )

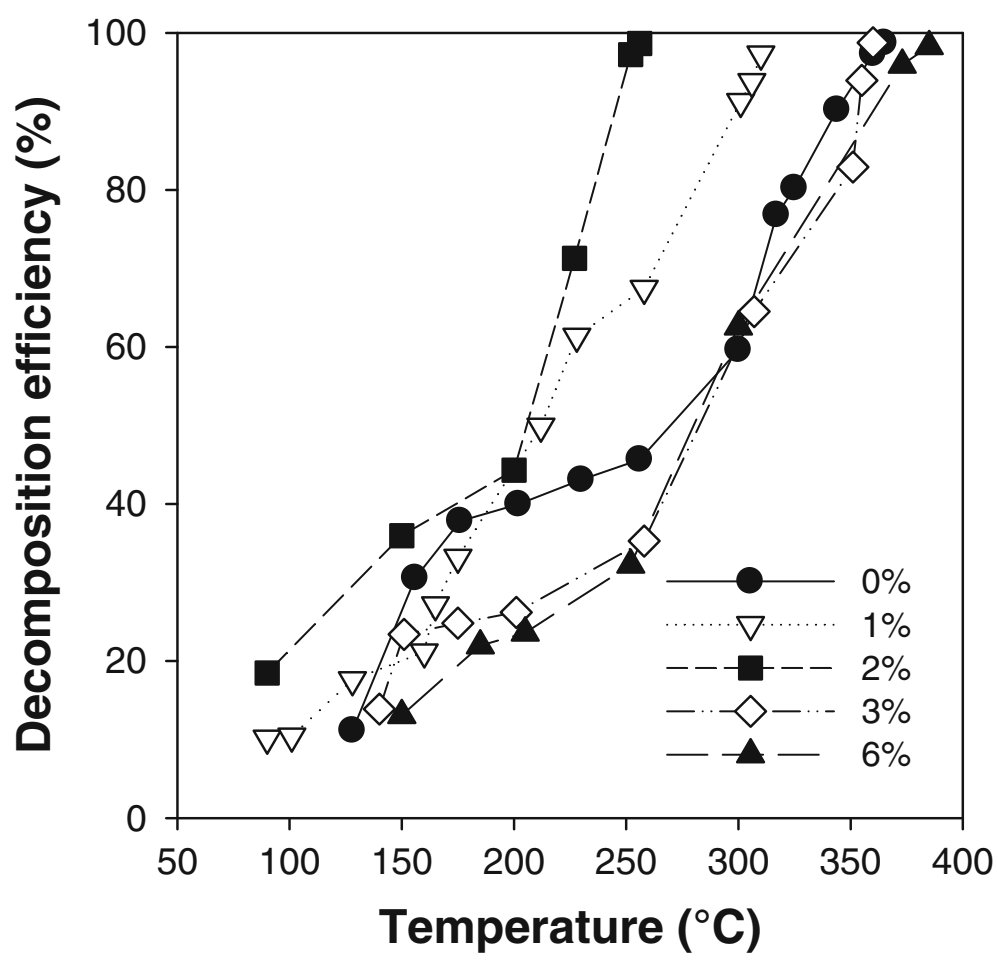

Fig. 7 FTIR spectra before and after plasma treatment [input power: $60 \mathrm{~W}$; initial HFC-134a: 2,000 ppm; oxygen: $2 \%(\mathrm{v} / \mathrm{v})]$

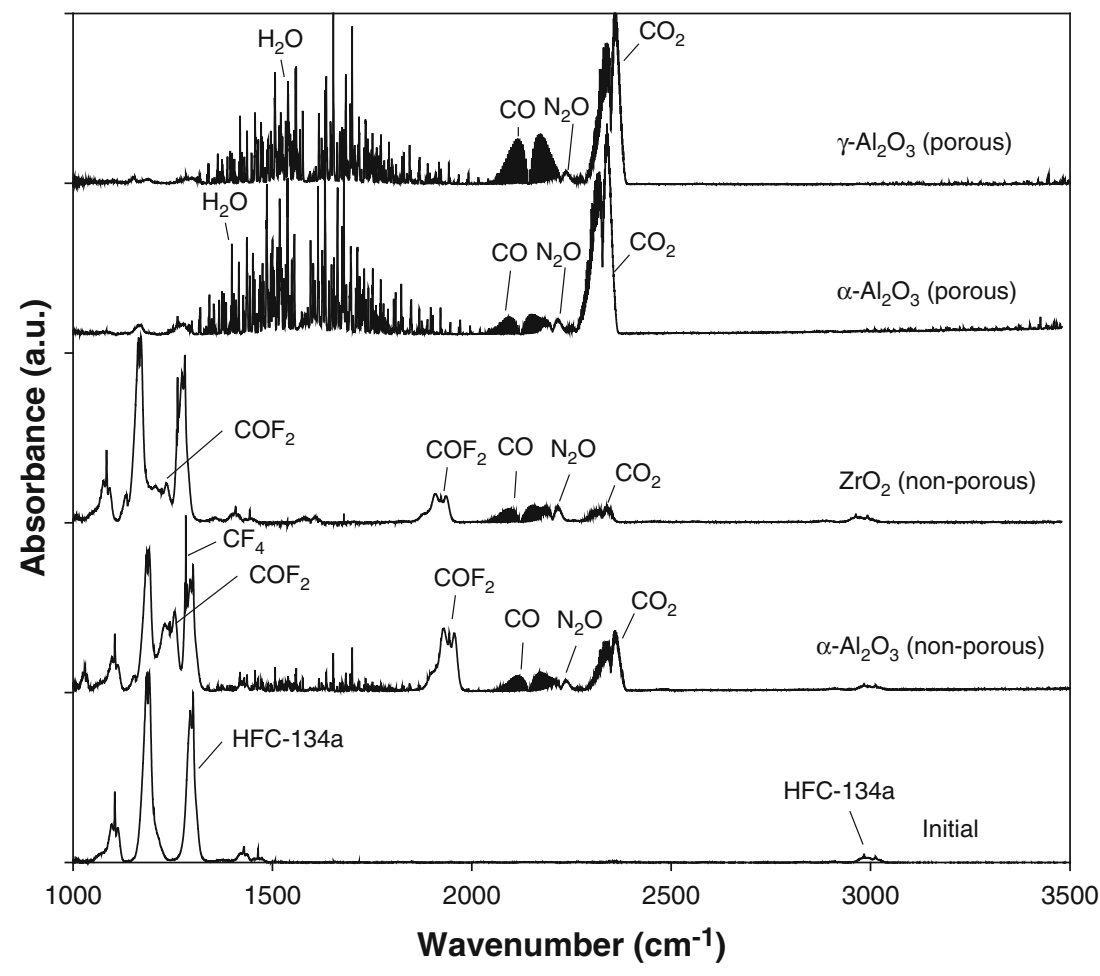

significant amount of $\mathrm{COF}_{2}$ was formed. The concentration of $\mathrm{COF}_{2}$ increased with increasing the temperature and then decreased with further increase in the temperature, showing maximum at around 300 and $170{ }^{\circ} \mathrm{C}$ for the nonporous $\alpha-\mathrm{Al}_{2} \mathrm{O}_{3}$ and $\mathrm{ZrO}_{2}$, respectively. Unlike the nonporous packing materials, $\mathrm{COF}_{2}$ was not detected with the porous $\gamma-\mathrm{Al}_{2} \mathrm{O}_{3}$ and $\alpha-\mathrm{Al}_{2} \mathrm{O}_{3}$ packing systems, suggesting that the combination of the nonthermal plasma with the porous $\mathrm{Al}_{2} \mathrm{O}_{3}$ turns the process toward total oxidation (Kim et al. 2010). In the porous $\gamma-\mathrm{Al}_{2} \mathrm{O}_{3}$ and $\alpha-\mathrm{Al}_{2} \mathrm{O}_{3}$, 

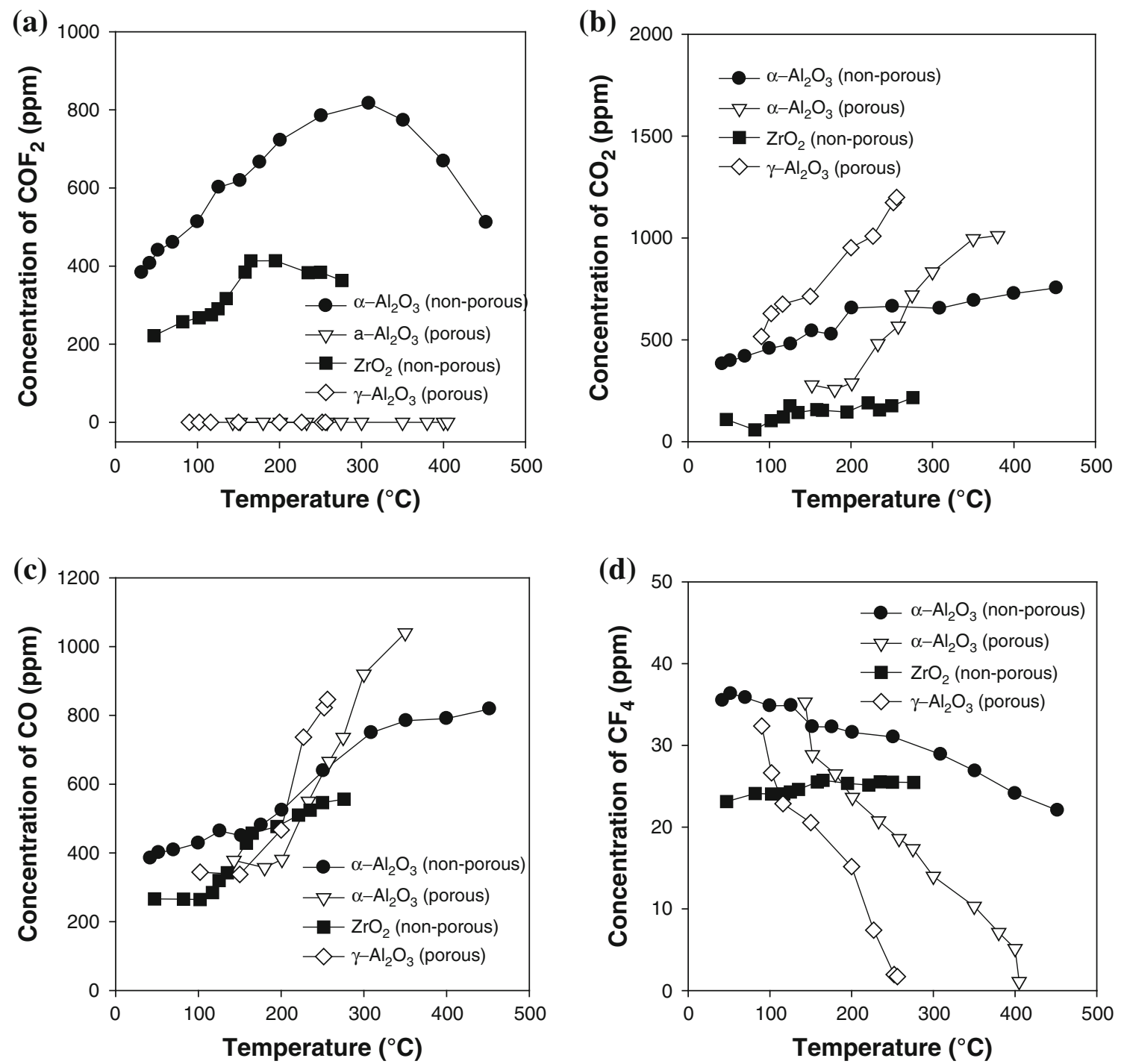

Fig. 8 Concentration profiles of byproducts over different packing materials. a $\mathrm{COF}_{2}, \mathbf{b ~} \mathrm{CO}_{2}$, $\mathbf{c} \mathrm{CO}$ and $\mathbf{d ~ C F} 4$ [input power: $60 \mathrm{~W}$; initial $\mathrm{HFC}$ 134a: 2,000 ppm; oxygen: $2 \%(\mathrm{v} / \mathrm{v})]$

$\mathrm{COF}_{2}$ must have been catalyzed into carbon oxides as soon as it was formed from the HFC-134a decomposition. It is likely that the oxidation of $\mathrm{COF}_{2}$ into carbon oxides by gas-phase reactions alone is hard to occur. The results obtained with the nonporous $\alpha-\mathrm{Al}_{2} \mathrm{O}_{3}$ and $\mathrm{ZrO}_{2}$ indicate that gas-phase reactions were dominant rather than catalytic reactions because the surface area was too limited to catalyze $\mathrm{COF}_{2}$.

The concentration profiles of $\mathrm{CO}_{2}$ and $\mathrm{CO}$ over different packing systems are shown in Fig. 8b, c. The concentrations of $\mathrm{CO}_{2}$ and $\mathrm{CO}$ increased sharply with the increase in the reactor temperature for the porous $\gamma-\mathrm{Al}_{2} \mathrm{O}_{3}$ and $\alpha$ $\mathrm{Al}_{2} \mathrm{O}_{3}$, but they only slowly increased with the nonporous $\alpha-\mathrm{Al}_{2} \mathrm{O}_{3}$ and $\mathrm{ZrO}_{2}$. Comparatively, larger amounts of $\mathrm{CO}_{2}$ and $\mathrm{CO}$ were produced by the porous $\gamma-\mathrm{Al}_{2} \mathrm{O}_{3}$ and $\alpha-\mathrm{Al}_{2} \mathrm{O}_{3}$, which is attributed to the enhanced decomposition of HFC134a, as easily understood from Fig. 3.

The concentration of $\mathrm{CF}_{4}$ from the decomposition of HFC-134a is depicted in Fig. 8d. The formation of $\mathrm{CF}_{4}$ is believed to result from the radical recombination between $\mathrm{CF}_{3}^{\circ}$ and $\mathrm{F}^{*}$. As shown, the suppression of $\mathrm{CF}_{4}$ in the porous $\gamma-\mathrm{Al}_{2} \mathrm{O}_{3}$ and $\alpha-\mathrm{Al}_{2} \mathrm{O}_{3}$ was superior to that in the nonporous $\alpha-\mathrm{Al}_{2} \mathrm{O}_{3}$. Furthermore, it was observed that the concentration of $\mathrm{CF}_{4}$ kept decreasing with increasing the reactor temperature in the presence of the porous $\gamma-\mathrm{Al}_{2} \mathrm{O}_{3}$ and $\alpha$ $\mathrm{Al}_{2} \mathrm{O}_{3}$. This result suggests that catalysis played an important role in preventing $\mathrm{CF}_{4}$ from forming by efficiently oxidizing the intermediate species to carbon oxides. Different from the porous packing materials, considerable amount of $\mathrm{CF}_{4}$ was retained even at high temperatures in 
the presence of the nonporous $\alpha-\mathrm{Al}_{2} \mathrm{O}_{3}$ and $\mathrm{ZrO}_{2}$. This result emphasizes again that the nonthermal plasma should be combined with the porous $\gamma-\mathrm{Al}_{2} \mathrm{O}_{3}$ and $\alpha-\mathrm{Al}_{2} \mathrm{O}_{3}$ capable of catalyzing intermediate species into carbon oxides.

\section{Conclusion}

The decomposition of HFC-134a with different packing systems was carried out using a DBD plasma reactor. The experimental results revealed that the porous $\gamma-\mathrm{Al}_{2} \mathrm{O}_{3}$ and $\alpha-\mathrm{Al}_{2} \mathrm{O}_{3}$ showed almost complete destruction of HFC-134a at 255 and $405{ }^{\circ} \mathrm{C}$, respectively, while the nonporous $\alpha$ $\mathrm{Al}_{2} \mathrm{O}_{3}$ and $\mathrm{ZrO}_{2}$ produced much lower decomposition efficiencies under the identical condition. Moreover, the porous $\gamma-\mathrm{Al}_{2} \mathrm{O}_{3}$ and $\alpha-\mathrm{Al}_{2} \mathrm{O}_{3}$ were capable of effectively preventing the formation of unwanted byproducts. With the nonporous $\alpha-\mathrm{Al}_{2} \mathrm{O}_{3}$ and $\mathrm{ZrO}_{2}$, considerable amounts of $\mathrm{COF}_{2}, \mathrm{CO}_{2}, \mathrm{CO}$ and $\mathrm{CF}_{4}$ were detected in the effluent gas. When the porous $\gamma-\mathrm{Al}_{2} \mathrm{O}_{3}$ and $\alpha-\mathrm{Al}_{2} \mathrm{O}_{3}$ were used as the packing material, however, $\mathrm{COF}_{2}$ was completely arrested and the formation of $\mathrm{CF}_{4}$ was well suppressed, promoting the production of $\mathrm{CO}_{2}$ and $\mathrm{CO}$. The plasma-catalytic combination was found to be suitable for treating a wide range of initial HFC-134a concentration. Despite twofold or threefold change in the initial concentration, the decomposition efficiency did not decrease that much. The addition of a small amount of oxygen around $2 \%$ was necessary either to improve the decomposition efficiency or to oxidize HFC-134a to carbon oxides.

Acknowledgments This work was carried out with the support of "Cooperative Research Program for Agriculture Science \& Technology Development (Project No. PJ008414)" Rural Development Administration, Republic of Korea.

\section{References}

Chen Z, Mathur VK (2003) Nonthermal plasma electrocatalytic reduction of nitrogen oxide. Ind Eng Chem Res 42:6682-6687
Futamura S, Gurusamy A (2005) Synergy of nonthermal plasma and catalysts in the decomposition of fluorinated hydrocarbons. J Electrost 63:949-954

Gandhi MS, Ananth A, Mok YS, Song JI, Park KH (2013a) Effect of porosity of $\alpha$-alumina on non-thermal plasma decomposition of ethylene in a dielectric-packed bed reactor. Res Chem Intermed. doi:10.1007/s11164-013-1053-Z

Gandhi MS, Mok YS, Lee SB, Park H (2013b) Effect of various parameters for butane decomposition under ambient temperature in a dielectric barrier discharge non-thermal plasma reactor. J Taiwan Inst Chem Eng 44:786-794

Holzer F, Roland U, Kopinke FD (2002) Combination of non-thermal plasma and heterogeneous catalysis for oxidation of volatile organic compounds: Part 1. Accessibility of the intra-particle volume. Appl Catal B Environ 38:163-181

Kang HC (2002) Decomposition of chlorofluorocarbon by nonthermal plasma. J Ind Eng Chem 8:488-492

Kim DH, Mok YS, Lee SB, Shin SM (2010) Nonthermal plasma destruction of trifluoromethane using a dielectric-packed bed reactor. J Adv Oxid Technol 13:36-42

Kogelschatz U (2003) Dielectric-barrier discharges: their history, discharge physics, and industrial applications. Plasma Chem Plasma Proc 23:1-46

Kuroki T, Mine J, Odahara S, Okubo M, Yamamoto T, Saeki N (2002) $\mathrm{CF}_{4}$ decomposition of flue gas from semiconductor process using inductively coupled plasma. In: Conference record of 37th IEEE industry applications society annual meeting, vol 3, pp 1810-1815

Ma H, Chen P, Zhang M, Lin X, Ruan R (2002) Study of $\mathrm{SO}_{2}$ removal using non-thermal plasma induced by dielectric barrier discharge (DBD). Plasma Chem Plasma Proc 22:239-254

Mok YS, Demidyuk V, Whitehead JC (2008) Decomposition of hydrofluorocarbons in a dielectric-packed plasma reactor. J Phys Chem A 112:6586-6591

Ohno M, Ozawa Y, Ono T (2007) Decomposition of HFC134a using arc plasma. Int J Plasma Environ Sci Technol 1(2):159-165

Stefanovic I, Bibinov NK, Deryugin AA, Vinogradov IP, Napartovich AP, Wiesemann K (2001) Kinetics of ozone and nitric oxides in dielectric barrier discharges in $\mathrm{O}_{2} / \mathrm{NO}_{\mathrm{x}}$ and $\mathrm{N}_{2} / \mathrm{O}_{2} / \mathrm{NO}_{\mathrm{x}}$ mixtures. Plasma Sources Sci Technol 10:406-416

Xu X-F, Jeon JY, Choi MH, Kim HY, Choi WC, Park Y-K (2007) The modification of stability of $\gamma-\mathrm{Al}_{2} \mathrm{O}_{3}$ based catalysts for hydrolytic decomposition of $\mathrm{CF}_{4}$. J Mol Catal A Chem 266: $131-138$

Yavorsky V, Znak Z (2009) Hydrogen sulfide decomposition in ultrahigh-frequency plasma. Chem Chem Technol 3:309-314

Zhu T, Li J, Jin YQ, Liang YH, Ma GD (2008) Gaseous phase benzene decomposition by nonthermal plasma coupled with nano titania catalyst. Int J Environ Sci Technol 6(1):141-148 